\title{
Commentary
}

\section{COVID-19 and Indian frontline workers}

\author{
Ankit Chaudhary ${ }^{1}$, Priyanka ${ }^{2 *}$, Shaina Chamotra ${ }^{3}$ \\ ${ }^{1}$ Department of Community Medicine, ${ }^{3}$ Department of Obstetrics \& Gynaecology, Dr. Rajendra Prasad Government \\ Medical College Kangra at Tanda, Himachal Pradesh India \\ ${ }^{2}$ District Program Officer, Office of Chief Medical Officer Sirmaur, Himachal Pradesh, India
}

Received: 09 July 2021

Accepted: 05 August 2021

\author{
*Correspondence: \\ Dr. Priyanka, \\ E-mail: priyanka08h@gmail.com
}

Copyright: $@$ the author(s), publisher and licensee Medip Academy. This is an open-access article distributed under the terms of the Creative Commons Attribution Non-Commercial License, which permits unrestricted non-commercial use, distribution, and reproduction in any medium, provided the original work is properly cited.

\begin{abstract}
The pandemic of COVID-19 has posed challenges and revealed so many shortcomings in vision and execution of health system. Despite of threats, it has also given ample opportunities for improvement in health care delivery. Health professional of each category has contributed beyond their capability in curbing the pandemic. Frontline workers like health workers and accredited social health activist (ASHA) workers have worked at the grass root level and given their absolute best despite their already stringent work schedule and job profile. Already trusted with so many health programs and community activities, they have excelled in management of the pandemic. However, this has posed a serious question and threat to already burdened health system. The pandemic has further worsened already compromised plight of frontline health personnel. It is high time that appropriate consideration be given to such workers in order to improve health system. Some form of appreciation in terms of monetary benefits, some administrative commendation or welfare measures must be thought to recognize their sincere efforts.
\end{abstract}

Keywords: COVID-19, Frontline worker, Health personnel

\section{INTRODUCTION}

COVID-19 pandemic has drastically changed the world in a short span of time making the whole world stand still. Simple yet often neglected measures such as hand washing and social distancing have become significant. ${ }^{1,2}$

Perhaps first time in the history of mankind, "prevention is better than cure" has been realized in its true sense. As bigger as the threat COVID has posed, an even bigger response has been made across the world to curb the pandemic. All health personnel ranging from accredited social health activist (ASHA) worker to clinicians, laboratory personnel to scientists, all have stepped up during this unexpected situation and contributed more than their capability. ${ }^{3}$ As much as the clinical health care personnel have provided care to the sick, the role of frontline workers who have directly worked in the community cannot be neglected. ${ }^{4}$

\section{Challenges for frontline workers}

Frontline workers are viewed as a backbone of health care system in India. Health workers and ASHA workers are usually the first contact of community with the health system. Frontline workers are assigned many significant jobs as their routine work profile such as antenatal and postnatal care, immunization, family planning services, treatment of common ailments, implementation of national health programs at most peripheral level, screening of diseases, field visits, health surveys, observation of health days, being part of village level committees, generation of awareness, health promotion, data compilation and reporting and countless other things. ${ }^{5,6}$ However, during pandemic the already overburdened workers have been further assigned additional responsibilities like active case finding, contact tracing, awareness generation, care of home isolated patients, vaccination, disposal of dead bodies etc. apart from their routine work. ${ }^{7}$ Despite this 
additional load, frontline workers have contributed more than enough to take care of health of the community at their own physical and mental expense.

However, there are some constraints which are challenging the working of frontline health personnel. It has been more than a year now, when India began its battle against pandemic. Health workers have become tired and exhausted after working constantly. Long duty hours, emergencies during odd timings, vaccination drive, additional jobs during these testing times have taken a toll on them, both physically and mentally. ${ }^{4}$ Many governments have prohibited the leaves for health personnel and allowing leaves only on extraordinary grounds. Moreover, due to depleted human health resource, many workers are not only working at their own place of posting but also have been deployed to vacant health institutions. Their family life is also getting affected due to such emergent situations. Without adequate renumerations and additional monetary benefits they are providing health services to the community, literally at their doorsteps.

Unfortunately, many health workers have also turned COVID positive which has affected their own health and also succumbed while battling the infection. ${ }^{8}$ Their family members are getting affected with the disease. Even disheartening to see is that instead of getting appreciation, many frontline health workers are getting harassed, embarrassed, misbehaved, threatened and even assaulted by community while discharging their duties. ${ }^{9,10}$

\section{Initiatives for frontline workers}

Since the pandemic began, frontline workers have been recognized as a key element in this fight. They have been labeled as "corona warriors" and "corona fighters" by the masses, administration, public representatives and media. Appreciation in terms of rewarding them by means of certificates, mementos has been carried out at different levels by different organizations. ${ }^{11}$ Nominal incentives have also been awarded to the front-line workers such as ASHA workers and Anganwadi workers for their added work during the pandemic. ${ }^{12}$ Certain insurance schemes have also been announced for the frontline workers keeping in mind any their adverse health outcomes while performing their duties. ${ }^{13}$ Such frontline health personnel were also vaccinated against COVID-19 on the priority basis and were one of the earliest recipients when the program was launched. ${ }^{14}$ Appreciation in any form tends to lift the morale of the workers and motivates them to perform with dedication.

\section{Recommendations}

While showering flowers and awarding health workers on stage looks great on media, these things sometimes are not enough to keep health workers engaged in this long fight. With each passing day, workers are getting more and more exhausted both physically and mentally. Working long hours without any holidays or vacations has further compromised their situation, demanding certain welfare measures for them. First of all, adequate human resource should be ensured at all levels. Despite so many years after independence, the proportion of health care personnel to population is far from acceptable, let alone recommended. So, recruitment of health personnel should be expedited and prioritized. Expenditure in health should be enhanced and a good chunk of GDP should be allocated keeping current circumstances in mind.

Respectable emoluments instead of meagre incentives must be provided to health care workers. Considering essentiality of health services, permanent recruitments should be made into different health cadres rather than appointing workers on contract or outsourcing on need basis. Ample rest, vacations and duties on rotation basis must be ensured to avoid exhaustion of the frontline workers. Appreciation and recognition at all levels must be accorded to the workers; exceptional and extra-ordinary personnel must be awarded. If any worker or their close family member gets infected, their treatment should be prioritized and dedicated beds should be identified for them in health institutions. Jobs for wards of workers who succumb while discharging their duties should be reserved as a homage to their supreme sacrifice during this unexpected occurrence. Frontline health personnel have always been an integral part of health system and without a shadow of a doubt, they have worked extremely hard in this pandemic phase. It is high time we recognize and appreciate their valiant efforts, protect them and do something for their welfare.

\section{Funding: No funding sources \\ Conflict of interest: None declared \\ Ethical approval: Not required}

\section{REFERENCES}

1. World Health Organization: Coronavirus disease (COVID-19) advice for the public. Available at: https://www.who.int/emergencies/diseases/novelcoronavirus-2019/advice-for-public. Accessed on 24 April 2021.

2. Centers for Disease Control and Prevention: How to Protect Yourself \& Others? Available at: https://www.cdc.gov/coronavirus/2019-ncov/preven t-getting-sick/prevention.html. Accessed on 24 April 2021.

3. Mehta S, Machado F, Kwizera A, Papazian L, Moss M, Azoulay E, et al. COVID-19: A heavy toll on health-care workers. The Lancet, Respiratory Medicine. 2021;9(3):226-8.

4. Oxford Policy Management: Understanding the role of Indian frontline workers in preventing and managing COVID-19. Available at: https://www.opml.co.uk/blog/understanding-therole-of-indian-frontline-workers-in-preventing-andmanaging-covid-19. Accessed on 27 April 2021. 
5. National Health Systems Resource Centre: Human Resources for Health, Model Job Descriptions. Available at: http://nhsrcindia.org/sites/default/files/Mode1\%20Jo b\%20Descriptions.pdf. Accessed on 29 May 2021.

6. Guidelines on Accredited Social Health Activists (ASHA). Available at: https://nhm.gov.in/images/ pdf/communitisation/task-group-reports/guidelineson-asha.pdf Accessed on 29 May 2021.

7. Role of Frontline Workers in Prevention and Management of Corona Virus. Available at: https://www.mohfw.gov.in/pdf/PreventionandMana gementofCOVID19FLWEnglish.pdf. Accessed on 29 May 2021.

8. 174 Doctors, 116 Nurses, 199 Health Workers died due to Covid: Centre. Available at: https://www.ndtv.com/india-news/174-doctors-116nurses-199-health-workers-died-due-to-covidcentre-2364200. Accessed on 28 April 2021.

9. Doctors, social workers attacked across India as country fights coronavirus, Business Standard April 02, 2020. Available at: https://www.businessstandard.com/article/pti-stories/in-coronaviruscrisis-sporadic-attacks-on-doctors-social-workerspolice-surface-120040201117_1.html. Accessed on 01 May 2021.

10. Locals in Lucknow Covid-19 hotspot stop health workers from examining people, India Today April 05, 2020. Available at: https://www.indiatoday .in/india/story/coronavirus-health-workers-heckledin-lucknow-sadar-bazaar-1663518-2020-04-05. Accessed on 01 May 2021.

11. Frontline warriors salute Corona Warriors and vow to continue supporting the fight, Ministry of Defence India Press Release, May 01 2020. Available at: https://pib.gov.in/PressReleasePage.aspx?PRID=16 96437. Accessed on 02 May 2021.

12. Himachal Govt. announces incentives for ASHA workers for contributing to COVID-19 fight, Republic Bharat May 27, 2020. Available at: https:/www.republicworld.com/india-news/generalnews/himachal-pradesh-coronavirus-covid-19-ashahealth-workers-incentives.html. Accessed on 02 May 2021.

13. Pradhan Mantri Garib Kalyan Package. Available at: https://www.mohfw.gov.in/pdf/MoFPMGaribKalya nYojanaPackage.pdf. Accessed on 02 May 2021.

14. Ministry of Health and Family Welfare India: COVID-19 Vaccines Operational Guidelines. Available at: https://www.mohfw.gov.in/pdf/ COVID19VaccineOG111Chapter16.pdf. Accessed on 04 May 2021.

Cite this article as: Chaudhary A, Priyanka, Chamotra S. COVID-19 and Indian frontline workers. Int J Res Med Sci 2021;9:2889-91. 